\title{
Effect of Osmotic Drying on Physicochemical Properties of Pansies (Viola $\times$ Wittrockiana)
}

\author{
Luana Fernandes ${ }^{\mathrm{a}}$ b, c , Susana Casal $^{\mathrm{b}}$, Agostinho Magalhães $^{\mathrm{a}}$, Paula Baptista $^{\mathrm{a}}$, \\ José A. Pereira a , Jorge A. SARAiva ${ }^{\mathrm{c}}$, And Elsa Ramalhosa ${ }^{\mathrm{a}^{*}}$ \\ ${ }^{\text {a }}$ Centro de Investigação de Montanha (CIMO)/School of Agriculture, Polytechnic Institute of Bragança, \\ Portugal \\ b LAQV@REQUIMTE/Laboratory of Bromatology and Hydrology, Faculty of Pharmacy, Porto University, \\ Portugal \\ c QOPNA \& LAQV-REQUIMTE, Department of Chemistry, University of Aveiro, Portugal \\ ${ }^{*}$ Corresponding author \\ elsaramalhosa@ipb.pt \\ TEL: $+351-273303308$ \\ FAX: $+351-273325405$
}

Received: 14 January 2018; Published online: 18 October 2019

\begin{abstract}
The objective of this work was to study the effect of osmotic drying, using different hypertonic solutions (sucrose and sodium chloride), on physicochemical characteristics of pansies (Viola $\times$ wittrockiana). The same treatments were applied to lettuce to compare the behavior of flowers with other vegetables. Pansies' superhydrophobic surface structure, called papillae, increased the resistance to exchanges with hypertonic solutions. No weight loss was observed after most treatments (sucrose: between 2.2 and $6.8 \%$; NaCl: between $-23.0 \%$ and $1.5 \%), \mathrm{a}_{w}$ maintained high values $(>0,94)$ and monomeric anthocyanins were preserved (fresh 0.10 and $0.19 \mathrm{mg}$ Cy-3glu/g fresh matter for $20 \% / 1 \mathrm{~h}$ in $\mathrm{NaCl}$ and $60 \% / 1 \mathrm{~h}$ in sucrose). When applying more drastic conditions, as sodium chloride for more than 1 hour, undesirable textural and color changes were observed. For lettuce, all treatments caused osmotic dehydration, weight loss (ranged between -9.3 to $-30.3 \%$ for $80 \% / 1 \mathrm{~h}$ in sucrose and $15 \% / 1 \mathrm{~h}$ in $\mathrm{NaCl})$ and a reduction in $\mathrm{a}_{w}(<0,97)$ and carotenoids, with sodium chloride causing more damage in visual appearance than sucrose. Therefore, immersion in osmotic solutions can be applied to lettuce but the desired effect was not achieved for pansies due to the morphological structure of the flowers' epidermis.
\end{abstract}

Keywords: Violaxwittrockiana; Lettuce; Osmotic dehydration; Carotenoids; Monomeric anthocyanins

\section{Introduction}

Garden pansies (Viola $\times$ wittrockiana) result from extensive hybridizing and selection involving the species of Viola tricolor, Viola lutea, $\mathrm{Vi}$ ola altaica and others (Lim, 2014). Pansies are edible flowers, added to salads or used to garnish desserts (frosted cakes, sorbets and iced drinks). They can also be crystallized and eaten as a sweet delicacy. Furthermore, these flowers are rich in health-promoting compounds, such as anthocyanins, carotenoids, flavonoids, potassium and phosphorus (Gamsjaeger, Baranska, Schulz, Heiselmayer, \& Musso, 2011; Rop, Mlcek, Jurikova, Neugebauerova, \& Vabkova, 2012; Vukics, Kery, \& Guttman, 2008), contributing for a healthy diet, while providing protection against cancer and cardiovascular diseases, among oth- 
ers (Lu, Li, \& Yin, 2016). However, edible flowers have a limited shelf-life, with petal abscission, discoloration, wilting, dehydration and tissue browning occurring soon after harvest. The most common ways to preserve edible flowers include refrigeration, drying or canning in sugar, and preservation in distillates. However, these processes can have a negative impact on their nutritional and sensory quality and appearance. In response to recent culinary trends, demanding an increased availability and shelf life of edible flowers, it is essential to find new technologies or pretreatments which are able to extend edible flowers' shelf life with minimal impact on their sensory and textural properties.

Immersion in osmotic solutions is a common procedure used to dehydrate foods, and it can be regarded as a way to decrease the water activity and maintain the appearance of pansies. However, few studies on the effect of osmotic dehydration have been conducted on edible flowers. This technology has already been applied to broccoli (Xin, Zhang, \& Adhikari, 2013) and cauliflower (Jayaraman, Das Gupta, \& Rao, 1990; Vijayanand, Chand, \& Eipeson, 1995), edible flowers less known by consumers, using sweet (sucrose or trehalose) and/or salty (ex: sodium chloride) approaches, but no studies on osmotic drying were found for pansies.

The main objective of the present work was to investigate the effect of osmotic dehydration in sucrose ( 60 and $80 \%, \mathrm{w} / \mathrm{v})$ and sodium chloride $(15 \%, 20 \%, 25 \%, \mathrm{w} / \mathrm{v})$ solutions, at room temperature, on the quality of pansies (Viola $x$ wittrockiana). Visual appearance, weight loss, $\mathrm{a}_{w}$ and color were evaluated before and after treatments. Simultaneously, the contents of carotenoids and monomeric anthocyanins were determined in the treated flowers. Lettuce, a leafy vegetable with a homogeneous color distribution, was used as a control, being subjected to the same treatments and evaluations.

\section{Materials and Methods}

\subsection{Samples}

Fresh white/violet pansies (Viola $\times$ wittrockiana) were collected at the greenhouse of the
School of Agriculture, Polytechnic Institute of Bragança (Bragança, Portugal) and transported immediately to the laboratory under refrigeration. The production mode was organic. Fresh lettuce was bought at a local market in Bragança city that is located in the Northeast of Portugal.

\subsection{Preparation of osmotic solutions}

The osmotic agents, sucrose and sodium chloride, were of commercial grade, purchased from a local market. The different concentrations of 60 and $80 \%(\mathrm{w} / \mathrm{v})$ of sucrose and $15 \%, 20 \%$ and $25 \%$ of sodium chloride were prepared by dissolving the required amounts of sucrose or sodium chloride in distilled water.

\subsection{Osmotic dehydration}

Pansies or lettuce leaves were placed into the vessels containing the different sucrose/sodium chloride solutions, remaining totally submerged. The ratio of raw material to osmotic solution was 1:4. At each sampling time (15 min, $30 \mathrm{~min}, 1 \mathrm{~h}$ and $2 \mathrm{~h}$ for sodium chloride / $1 \mathrm{~h}$ and $2 \mathrm{~h}$ for sucrose), the flowers and lettuce leaves were taken out, gently dried with adsorbent paper and weighed. These conditions were selected after several preliminary tests, where higher times and mechanical agitation were shown to induce degradation. Each treatment/time was performed in triplicate, on both pansies and lettuce.

A portion of each sample, including fresh ones, was immediately analyzed for weight, $\mathrm{a}_{w}$, color, and microscopy, while the remainder was preserved by freeze-drying for analysis of bioactive compounds, as detailed in Section 2.4.

\subsection{Physicochemical characterization of samples}

\section{Color, water activity $\left(\mathbf{a}_{w}\right)$ and weight loss}

The color of pansies (white and violet parts) and lettuce were evaluated in three samples of each treatment/time, with a colorimeter Minolta CR400 (Osaka, Japan), using CIE Lab mode. $L^{*}$, 
$a^{*}$ and $b^{*}$ coordinates were measured, where $L^{*}$ varies between 0 (completely black) and 100 (completely white), $a^{*}-100$ (green) to +100 (red), and $b^{*}$ from -100 (blue) to +100 (yellow). Furthermore, the Chroma $\left(C^{*}\right)$ and Hue Angle $\left(h^{*}\right)$ values were determined. In order to analyse the color variations, the total color difference $\left(\Delta E^{*}\right)$ was also calculated, according to equation 1:

$$
\Delta E^{*}=\sqrt{\left(\Delta L^{*}\right)^{2}+\left(\Delta b^{*}\right)^{2}+\left(\Delta a^{*}\right)^{2}}
$$

where $\Delta$ was the difference between the parameters' values after the immersion in osmotic solutions and before it (fresh sample).

Water activity $\left(\mathrm{a}_{w}\right)$ was determined in a portable water activity meter (Novasina, LabSwift-a ${ }_{w}$, Lachen, Switzerland). This parameter was evaluated on three samples before treatment (control) and after immersion in the osmotic solutions. Weight measured in a digital balance (Kern ACJ/ACS, Balingen, Germany), is the weight variation expressed in relative percentage of initial weight.

\section{Freeze-dried}

Flowers and lettuce, treated and untreated, were frozen and lyophilized (Scanvac, Coolsafe, Lynge, Denmark) for 2 days. They were ground to a homogenous powder and then stored for protection from light and moisture until extraction.

\section{Carotenoids}

The carotenoids content was determined according to the method used by Aquino-Bolaños, Urrutia-Hernandez, Lopez Del Castillo-Lozano, Chavez-Servia, and Verdalet-Guzman (2013). One gram of frozen-dried powder of the osmotic dehydrated and fresh pansies and lettuce was extracted twice with $20 \mathrm{ml}$ acetone:hexane solution $(1: 1, \mathrm{v} / \mathrm{v})$. Both extracts were put into a separation funnel, where $200 \mathrm{ml}$ of distilled water was added to eliminate acetone. The acetonefree phase was mixed with $5 \mathrm{~g}$ anhydrous sodium sulphate to eliminate any residual water. The remaining solution was filtered and completed to $100 \mathrm{ml}$ with hexane. Carotenoids content was determined by reading the absorbance at $450 \mathrm{~nm}$ and comparing the result to a $\beta$-carotene calibration curve $(0.22-8.8 \mu \mathrm{g} / \mathrm{ml})$. Results were expressed in $\mu \mathrm{g} \beta$-carotene/g fresh matter.

\section{Monomeric anthocyanins}

Extraction was based on the method described by $\mathrm{Li}$ et al. (2014) with slight modifications. Dried powdered sample $(0.5 \mathrm{~g})$ was extracted with $20 \mathrm{ml}$ of methanol, at $37^{\circ} \mathrm{C}$, for $30 \mathrm{~min}$ under agitation (IKA, RCT Model B, Staufen, Germany) at a frequency of $900 \mathrm{rpm}$. The methanol extracts were filtered and concentrated in a rotary evaporator (Stuart RE3022C, Staffordshire, United Kingdom), frozen and lyophilized for 2 days. The extract obtained was re-dissolved with methanol to a concentration of $50 \mathrm{mg}$ extract $/ \mathrm{ml}$, covered with aluminium foil and preserved under freezing conditions until further analysis.

The total monomeric anthocyanin contents of fresh pansies and lettuce, as well as of the samples immerged in the osmotic solutions, were estimated by the $\mathrm{pH}$ differential method, following the methodologies used by Bchir et al. (2012) and (Rajasekar, Akoh, Martino, \& MacLean, 2012). The method consisted of using two buffer systems: potassium chloride buffer at $\mathrm{pH} 1.0(0.025$ $\mathrm{M})$ and sodium acetate at $\mathrm{pH} 4.5(0.4 \mathrm{M})$. Extracts' portions were diluted on both buffers, and allowed to stand for $30 \mathrm{~min}$ at room temperature. Subsequently, the absorbance readings were made on a UV-Visible spectrophotometer (Thermo, Genesys 10 UV, Waltham, USA) at the wavelengths of 510 and $700 \mathrm{~nm}$, and the absorbance difference (A) determined by equation 2 :

$A=\left(A_{510 n m}-A_{700 n m}\right)_{p H 1.0}-\left(A_{510 n m}-A_{700 n m}\right)_{p H 4.5}$

The monomeric anthocyanin pigment concentration was expressed as cyanidin-3-glucoside and was determined by equation 3 :

$$
M A P=A \times M W \times D F \times \frac{1000}{\varepsilon}
$$

where $\mathrm{MAP}=$ Monomeric anthocyanin pigment (mg Cy 3-glu/l) MW= molecular weight (449.2), $\mathrm{DF}=$ dilution factor and $\varepsilon=$ Molar absorptivity $(26,900)$. All measurements were performed in triplicate. The results were expressed in $\mathrm{mg} \mathrm{Cy}$ 3 -glu/g fresh matter. 


\subsection{Microscopic analysis of pansies petals}

Thin sections of petals were cut into random transversal and longitudinal sections, mounted in glycerin (previously dehydrated in an upward series of ethanol) and observed on a light microscope equipped with a digital camera (Leica DFC49012, Heerbrugg, Switzerland). The structure of the petals' epidermis was analyzed at different points.

\subsection{Statistical analysis}

The SPSS Statistical software, v.18.0 (SPSS Inc., Chicago, IL), was used for the statistical treatment of the data. The normality of the data was verified by the Shapiro-Wilk test. Analysis of variance (ANOVA) or ANOVA Welch was carried out to determine if there were significant differences $(\mathrm{p}<0.05)$ between samples, depending on the existence or not of homogeneity of variances. Additionally, if significant differences were detected between treatments, a post hoc analysis was performed, namely: the Tukey's honestly significant difference test, if variances in the different groups were identical, or Games-Howell test if they were not. The homogeneity of the variances was tested by Levene's test.

\section{Results and discussion}

\subsection{Visual appearance and color}

Figure 1 shows the visual appearance of fresh pansies and lettuce before and after treatments with different concentrations and immersion times in osmotic solutions (sucrose and sodium chloride). Flowers and lettuce subjected to the four treatments with sucrose $(1 \mathrm{~h}$ or $2 \mathrm{~h}$ at 60 and $80 \%$ ) and lower concentration of sodium chloride (15\% for 15 or $30 \mathrm{~min}$ ) showed similar appearance to fresh samples. However, when higher concentrations of sodium chloride (20 and 25\%) or longer immersion times ( 1 and $2 \mathrm{~h}$ ) were applied, structural damage was observed, as well as color changes. Furthermore, when pansies were removed from these higher concentrated osmotic salt solutions they shrank, making them more fragile. Lettuce leaves also became more brittle and showed a darkening in color.

The total color difference, $\Delta E^{*}$, which is a combination of $L^{*}, a^{*}$ and $b^{*}$ values, is a colorimetric parameter used to characterize the variation of colors in food during different treatments. For pansies and lettuce, higher values of $\Delta E^{*}$ and standard deviations were observed in samples treated with sodium chloride (Fig. 2 and 3, respectively). Taking into account that a $\Delta E^{*}$ of up to 3 CIELab units indicates color differences appreciable to the human eye (Trivellini et al., 2014), both samples showed color differences detectable by consumers after treatments. Regarding pansies, a distinct behavior was observed in the two colored parts studied, white and violet. Generally, the white part showed lower values of $\Delta E^{*}$ than the violet one, without significant differences between treatments in the white part, with the exception of the treatment $15 \% \mathrm{NaCl}$ for $1 \mathrm{~h}$. On the contrary, the violet part was more color sensitive, with the more significant alterations observed with the following treatments: $80 \%$ sucrose/2h, $15 \% \mathrm{NaCl} / 15 \mathrm{~min}$, $15 \% \mathrm{NaCl} / 30 \mathrm{~min}$, and $15 \% \mathrm{NaCl} / 2 \mathrm{~h}$. Lettuce, probably due to its increased color homogeneity, showed constant values of $\Delta E^{*}$, without significant differences detected between treatments, except for $60 \%$ sucrose $/ 2 \mathrm{~h}$.

\subsection{Weight and $\mathbf{a}_{w}$ variation}

Immersion time and sucrose/sodium chloride concentration effects on weight and $\mathrm{a}_{w}$ variation in pansies and lettuce are also given in Fig. 2 and 3 , respectively.

Pansies' weight (Fig. 2) showed significant increases in both osmotic solutions among treatments. It could be expected that, after immersion treatment, pansies should lose weight due to diffusion of water, even though accompanied by simultaneous counter diffusion of solutes from the osmotic solution into the tissue. Furthermore, it is desired to have a high water loss for preservation purposes and a low solids gain, which will lead to high weight variations. These exchanges of solute and water probably did not happen because pansies' petals have a structure named papillae (conical epidermal cells) in the

\begin{tabular}{l|l|l|l} 
IJFS & October 2019 & Volume 8 & pages 23-33
\end{tabular} 


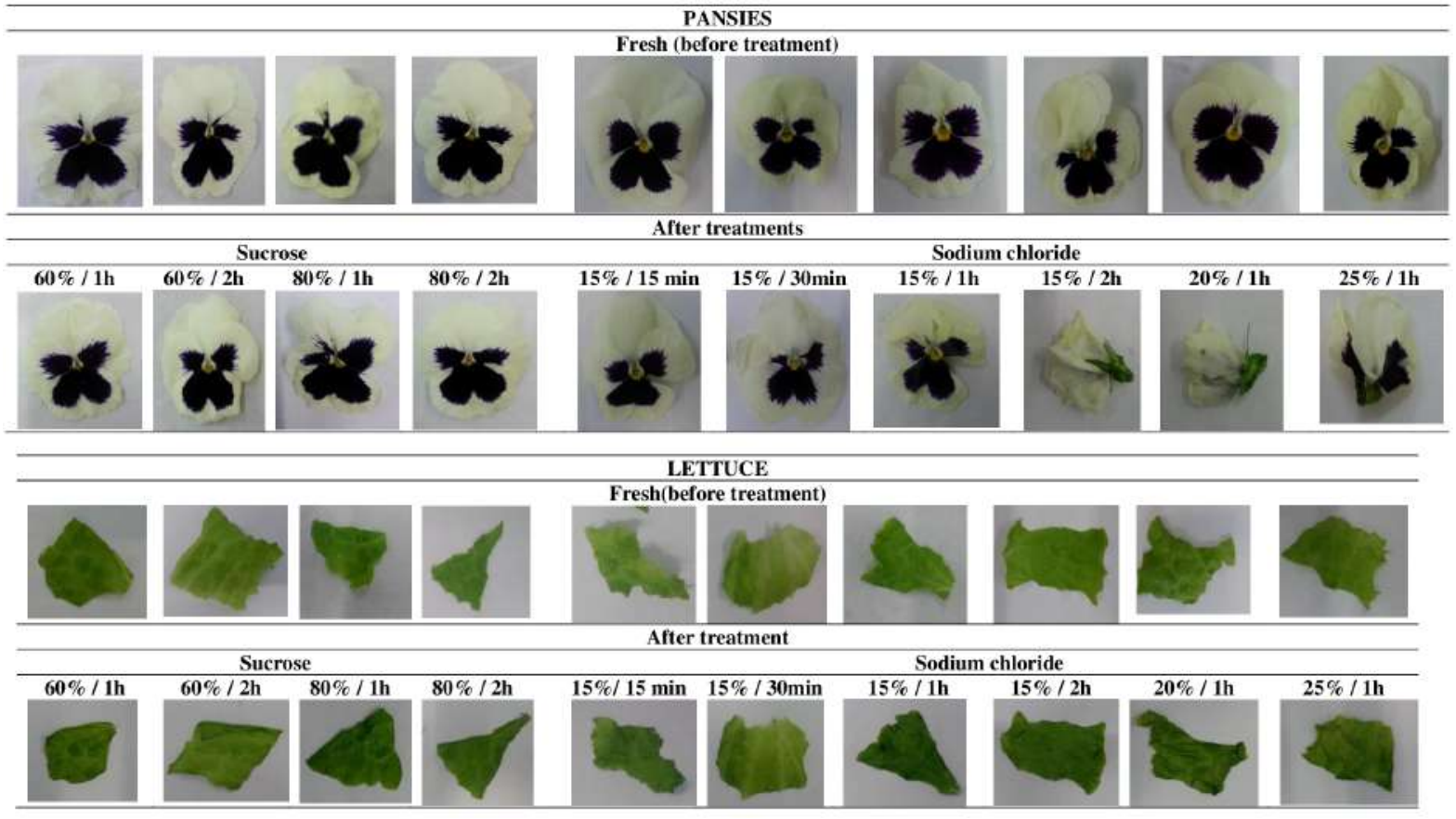

Figure 1: Visual appearance of pansies (A) and lettuce (B) before and after immersion in osmotic solutions with sucrose and sodium chloride

epidermis on both sides of all the petals (spurred, lateral and upper) (Weryszko-Chmielewska \& Sulborska, 2012) and this structure has been reported to be superhydrophobic (Schulte, Droste, Koch, \& Barthlott, 2011). In the present work, we observed pansies' petals by microscopy (Fig. 4). The papillae were very visible, explaining the obtained results. In some situations, the increased weight observed in pansies could be due to some sugar or salt dried on the outside of the flowers. However, when salt was used in different concentrations $(15,20,25 \%)$ during 1 hour, pansies lost weight because probably some cell rupture occurred, contributing to the bad visual appearance (Fig. 1). Regarding lettuce, all treatments induced weight loss, giving rise to effective osmotic dehydration. Comparing different concentrations of sucrose $(60 \%$ and $80 \%)$ at $1 \mathrm{~h}$ of immersion, $80 \%$ of sucrose was less effective than at $60 \%$. This is in line with Ponting, Watters, Forrey, Jackson, and Stanley (1966), who stated that above $60 \%$ sugar concentration, an additional increase in sugar concentration did not promote further water loss in vegetables. However, a decreased weight can be observed in lettuce by increasing the immersion time (1 and 2 hours) for both sucrose concentrations. Regarding salt treatments, lettuce showed a higher decrease in weight with higher times of immersion (more than $30 \mathrm{~min}$ ). However, it was observed that the effect was not as evident as when the concentrations of the osmotic solution increased. Based on these observations, it seems that pansies' structure does not allow the exchange of solutes with osmotic solutions, and therefore is not adequate for osmotic drying.

Low water activity reduces the growth of microorganisms and decreases biochemical reactions, which is important for the preservation of food. Regarding the water activity $\left(\mathrm{a}_{w}\right)$ values in pansies, the highest values were obtained in fresh samples. A decrease in $\mathrm{a}_{w}$ values was observed after all treatments, except with $15 \% \mathrm{NaCl}$ for 30 min. However, when using sucrose no significant differences were detected between treatments. With $\mathrm{NaCl}$, higher contact times (ex: 1 
A) Sucrose
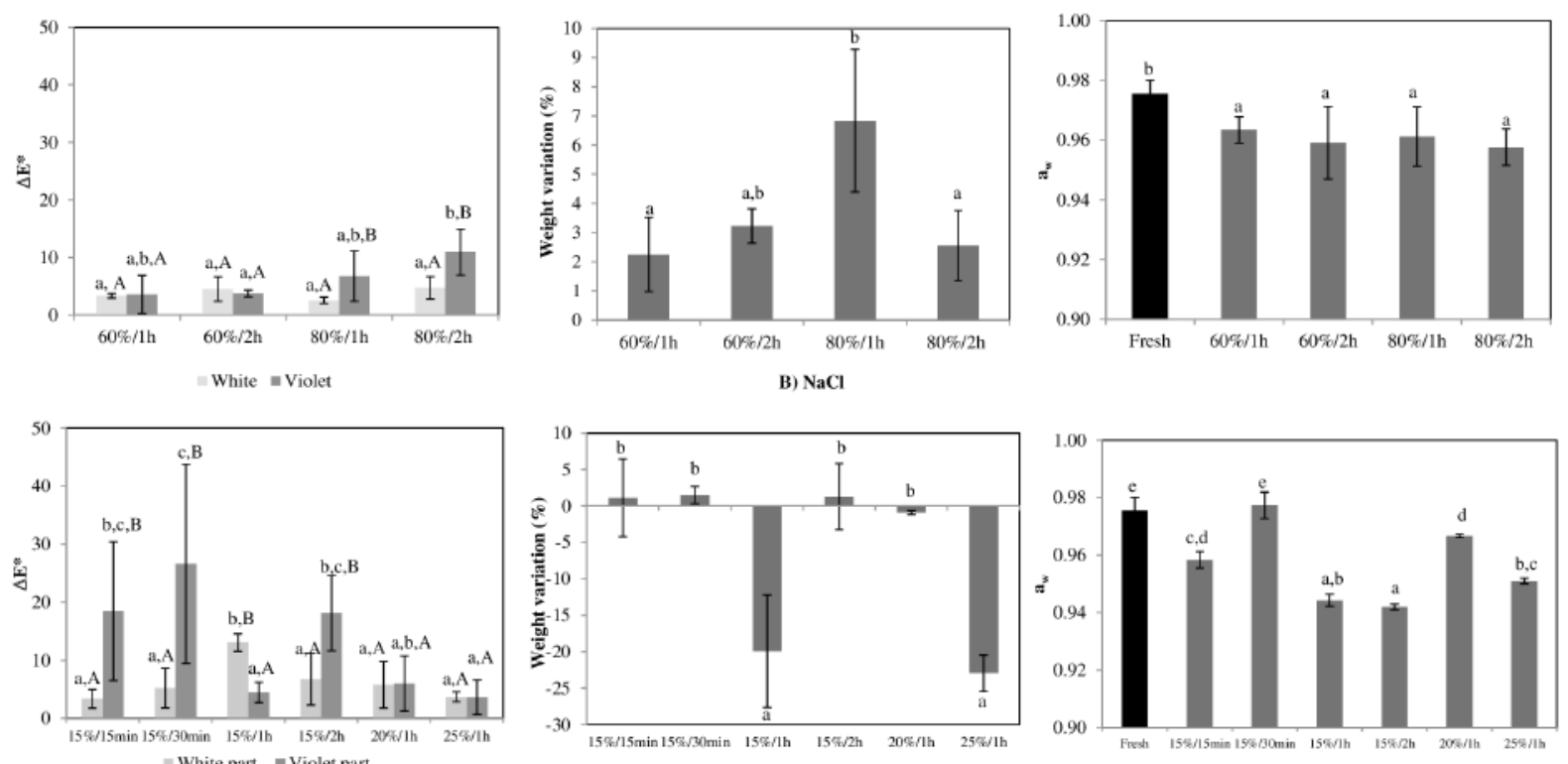

Figure 2: $\mathrm{a}_{w}$, weight $(\%)$ and $\Delta E^{*}$ variation before and after pansies treatments with sucrose (A) and sodium chloride (B) solutions (lower letters compare treatments while caps compare different parts of pansies (white and violet). Values with the same letter are not statistically different $(\mathrm{p}>0.05))$
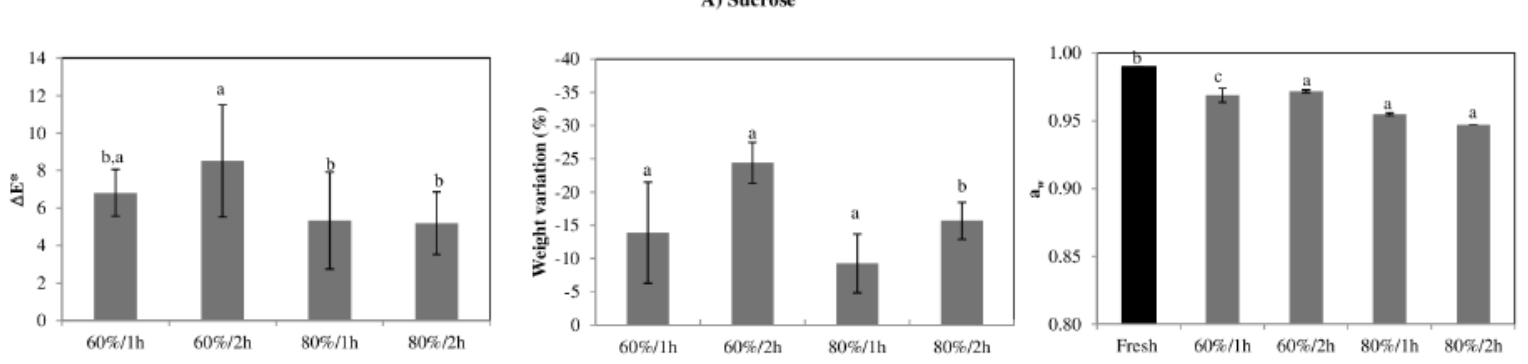

B) $\mathrm{NaCl}$
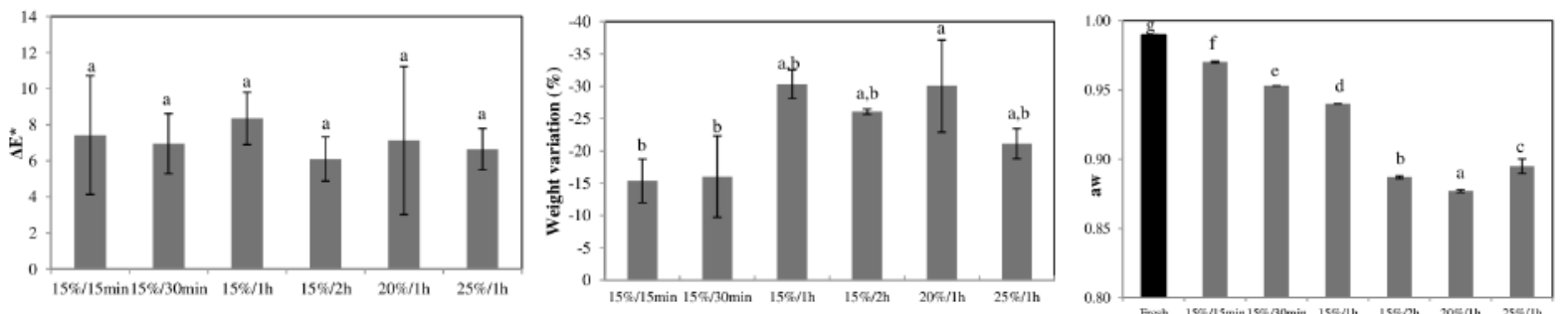

Figure 3: $\mathrm{a}_{w}$, weight variation and $\Delta E^{*}$ contents before and after lettuce treated with sucrose $(\mathrm{A})$ and sodium chloride (B) solutions 


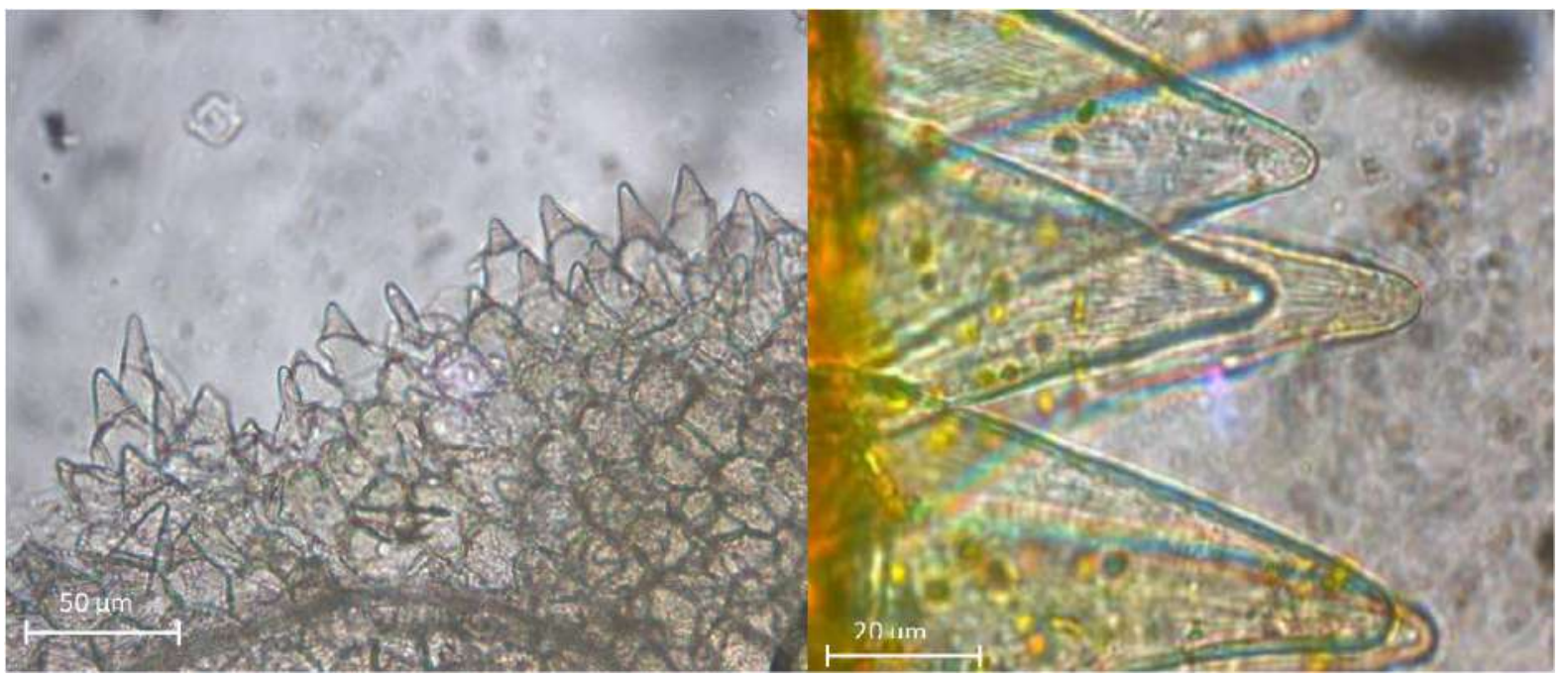

Figure 4: Conical papillae on the surface of Viola $\times$ wittrociana

and $2 \mathrm{~h}$ at $15 \%, \mathrm{w} / \mathrm{v}$ ) or higher salt concentrations (20 and 25\%; w/v) caused an effective decrease in the $\mathrm{a}_{w}$ values. As expected for lettuce subjected to different osmotic solutions, $\mathrm{a}_{w}$ values also decreased compared to the fresh sample. In general, increased immersion times and concentrations induced a decrease in $\mathrm{a}_{w}$, with a linear decreasing effect. Furthermore, this decrease was more pronounced when using sodium chloride as an osmotic solution.

\subsection{Carotenoids}

Fig. 5 presents the carotenoids content of pansies (A) and lettuce (B) before and after immersion in osmotic solution. The highest concentrations were observed in the fresh sample for pansies and lettuce (75.7 and $72.8 \mu \mathrm{g} \beta$-carotene /g fresh matter, respectively). In general, a decrease of carotenoids content was observed with the osmotic treatments. This decrease might be due to partial leaching of these pigments as the osmotic stress increased, due to the breakage of the cell structures (Tadesse, Abera, \& Worku, 2015), or the susceptibility of carotenoids to oxidation, isomerisation and other chemical changes during processing because of their extensive conjugated double-bond systems (Shi \& Le Maguer, 2000).
Samples immersed in sucrose showed lower contents of carotenoids than in sodium chloride. The effect of different concentrations of osmotic solutions and immersion time on carotenoids content of lettuce and pansies were significant $(\mathrm{p}<0.05)$. For pansies, the best conditions to retain the highest amount of carotenoids was $15 \%$ sodium chloride with $30 \mathrm{~min}$ of immersion, and for lettuce was $15 \%$ of sodium chloride for $15 \mathrm{~min}$. For pansies, when using sucrose, no significant differences were obtained between treatments.

\subsection{Monomeric anthocyanins}

The total monomeric anthocyanins content in fresh pansies and those immersed in osmotic solutions are shown in Fig. 6A (sucrose) and 6B $(\mathrm{NaCl})$. Lettuce anthocyanins, if present, were below the detection limit.

Anthocyanins are the main compounds responsible for the wide range of colors in pansies. Some authors report that the anthocyanins present in the Viola species are formed from malvidin, peonidin and petunidin anthocyanidins (Gamsjaeger et al., 2011; Skowyra, Calvo, Gallego, \& Azman, 2014; Zhang et al., 2012). From all the treatments, only immersion in $60 \%$ sucrose during $1 \mathrm{~h}$ induced a significant increase of to- 


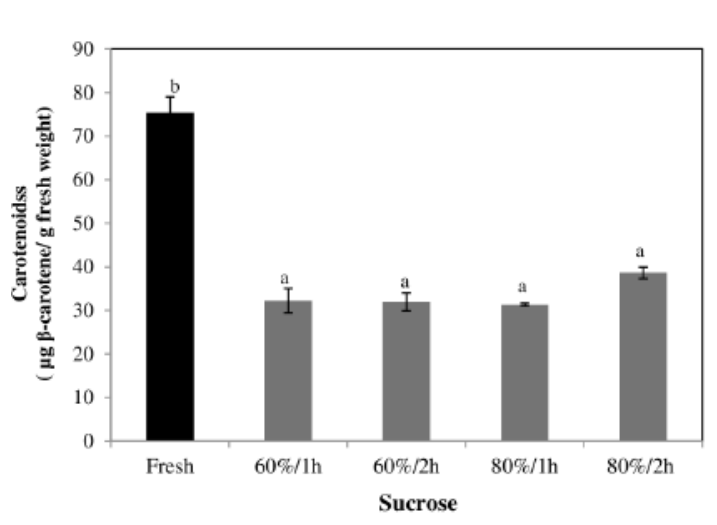

A) Pansies
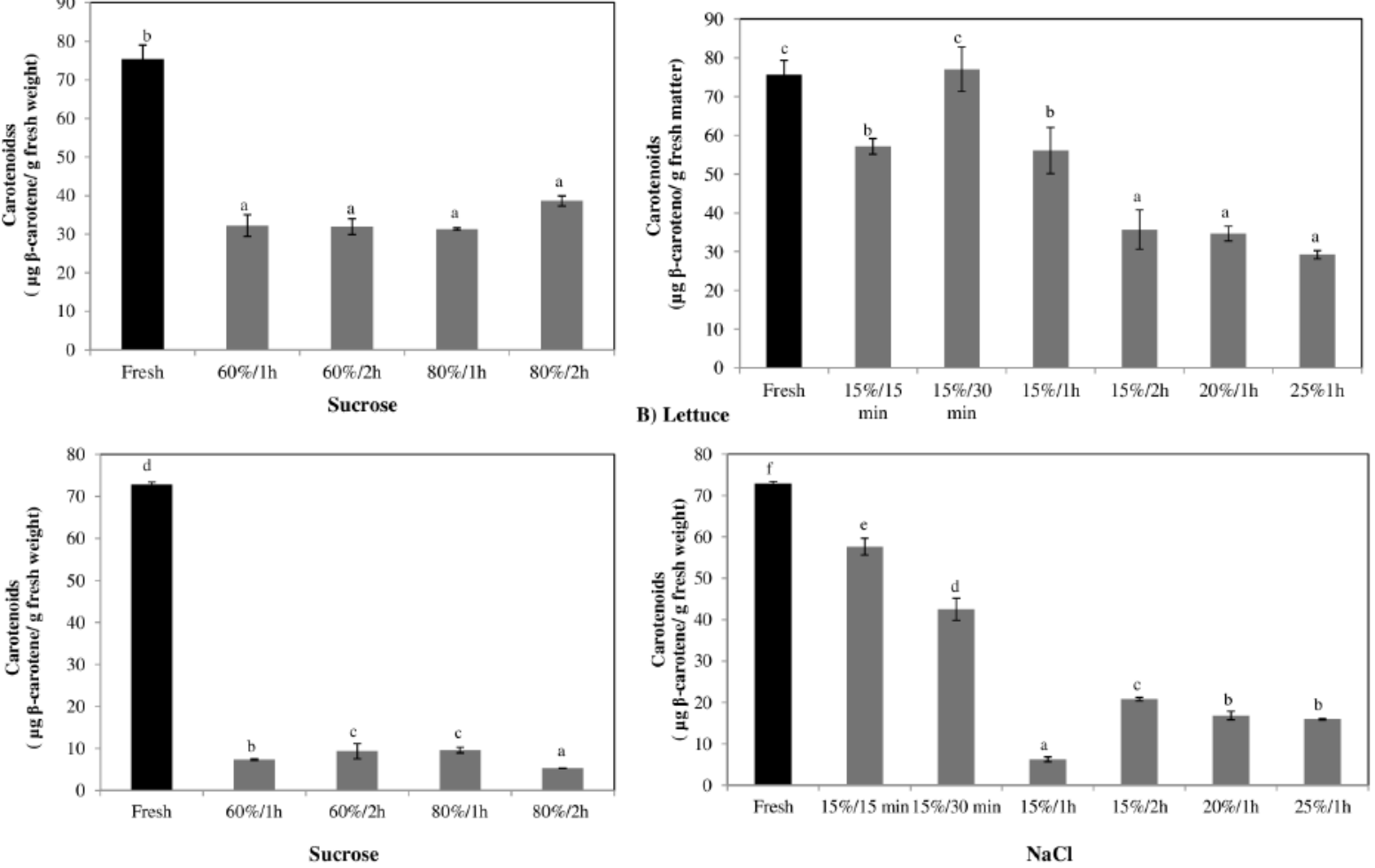

B) Lettuce

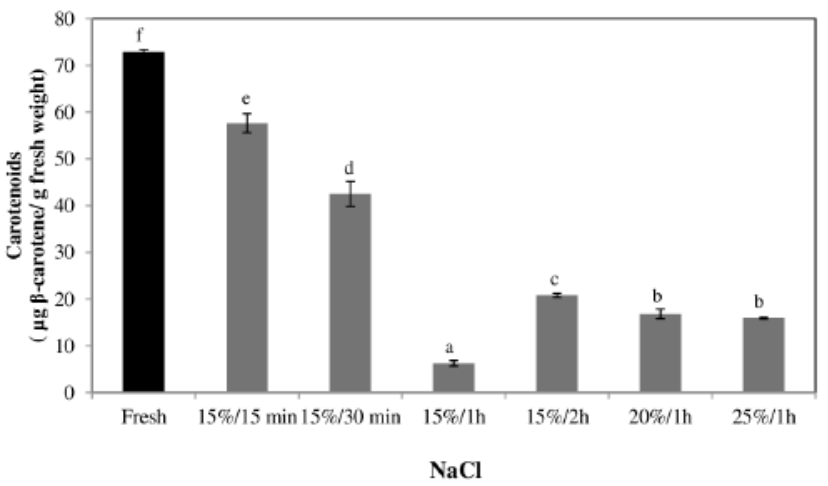

Figure 5: Carotenoids content ( $\mu \mathrm{g} \beta$-carotene/g fresh matter) before and after pansies (A) lettuce (B) treatments with sucrose solutions and sodium chloride
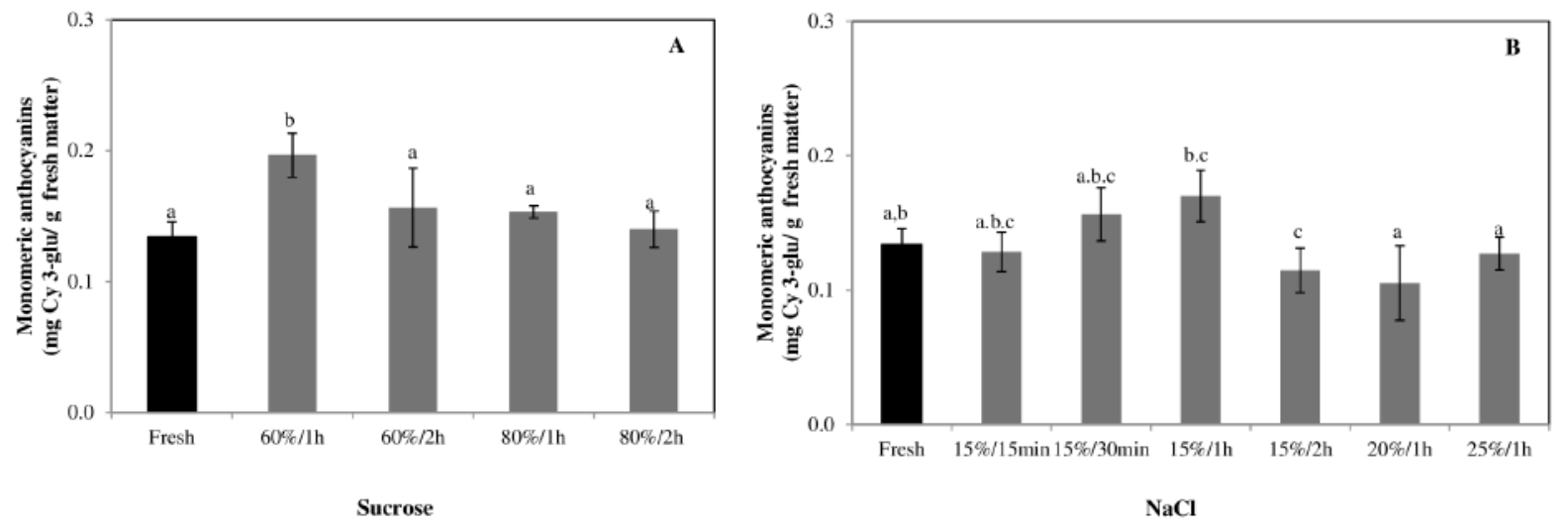

Figure 6: Monomeric anthocyanins content (mg Cy 3-G/g fresh matter) before and after pansies treatments with sucrose and sodium chloride solutions 
tal monomeric anthocyanins compared with fresh samples. A direct interpretation of this result is not as expected because anthocyanins are soluble in water and they exist in epidermal and subepidermal cells, dissolve in vacuoles or accumulate in vesicles called anthocyanoplasts (Karami, Yousefi, \& Emam-Djomeh, 2013). Therefore, they could leak into the osmotic medium through the cuticle and skin ruptures (Karami et al., 2013). Within the other sucrose treatments, no significant differences were observed between assays, and no indications of degradation or leaching of these compounds existed. Furthermore, the sugar concentrations applied in the present work were not sufficient to increase the $\mathrm{pH}$ of the solution, which may raise the percentage of anthocyanins in the colourless carbinol base form that is very unstable, making the pigment more susceptible to degradation by oxygen (Karami et al., 2013; Stojanovic \& Silva, 2007).

For $\mathrm{NaCl}$, only the treatment with $15 \%$ and $2 \mathrm{~h}$ of immersion caused a decrease of the monomeric anthocyanins content when compared to the fresh state. This result might be due to the increase in the contact time of pansies in the sodium chloride solution leading to an increase in osmotic pressure and enhanced water loss. High water loss resulted in a higher loss of anthocyanins because they are water-soluble pigments.

\section{Conclusions}

In summary, pansies present a superhydrophobic structure that increases the resistance to osmotic dehydration with both sucrose and sodium chloride solutions. In general, when pansies were submitted to osmotic solutions, an almost general weight gain, $\mathrm{a}_{w}$ maintenance and high monomeric anthocyanins contents were observed. However, high concentrations of sodium chloride induced damage in pansies' structure and color alterations. Compared to pansies, all treatments applied to lettuce caused effective osmotic dehydration, with weight loss and reduced $\mathrm{a}_{w}$, as expected when performing the osmotic dehydration of vegetables. So, immersion in osmotic solutions cannot be applied to pansies due to their morphological structure, namely the presence of papillae (conical epidermal cells) that are extremely hydrophobic.

\section{Acknowledgements}

The authors acknowledge the Portuguese Foundation for Science and Technology (FCT, Portugal) for the financial support provided by the research grant $\mathrm{SFRH} / \mathrm{BD} / 95853 / 2013$ and $\mathrm{FCT} / \mathrm{MCT}$ for the financial support to QOPNA research Unit (FCT UID/QUI/00062/2019), through national funds and where applicable cofinanced by the FEDER, within the PT2020 Partnership Agreement, to the Portuguese NMR Network and to REQUIMTE through the Project PEst/ UID/QUI/50006/2013. The authors are also grateful to the Foundation for Science and Technology (FCT, Portugal) and FEDER under Programme PT2020 for financial support to CIMO (UID/AGR/00690/2019).

\section{References}

Aquino-Bolaños, E. N., Urrutia-Hernandez, T. A., Lopez Del Castillo-Lozano, M., Chavez-Servia, J. L., \& Verdalet-Guzman, I. (2013). Physicochemical parameters and antioxidant compounds in edible squash (Cucurbita Pepo) flower stored under controlled atmospheres. Journal of Food Quality, 36 (5), 302-308. doi:10.1111/jfq.12053

Bchir, B., Besbes, S., Karoui, R., Attia, H., Paquot, M., \& Blecker, C. (2012). Effect of air-drying conditions on physicochemical properties of osmotically pretreated pomegranate seeds. Food and Bioprocess Technology, 5(5), 1840-1852. doi:10.1007/s11947-010-0469-3

Gamsjaeger, S., Baranska, M., Schulz, H., Heiselmayer, P., \& Musso, M. (2011). Discrimination of carotenoid and flavonoid content in petals of pansy cultivars (Viola $x$ wittrockiana) by ft-raman spectroscopy. Journal of Raman Spectroscopy, 42(6), 12401247. doi:10.1002/jrs.2860

Jayaraman, K. S., Das Gupta, D. K., \& Rao, N. B. (1990). Effect of pretreatment with salt and sucrose on the quality and stability of dehydrated cauliflower. International 
Journal of Food Science and Technology, 25(1), 47-60.

Karami, Z., Yousefi, G., \& Emam-Djomeh, Z. (2013). Modeling and optimization of ultrasound-assisted osmotic dehydration with finished freeze drying on black cherries - the effect on antioxidant activities.

Li, A.-N., Li, S., Li, H.-B., Xu, D.-P., Xu, X.-R., \& Chen, F. (2014). Total phenolic contents and antioxidant capacities of 51 edible and wild flowers. Journal of Functional Foods, 6, 319-330. doi:10.1016/j.jff.2013.10.022

Lim, T. K. (2014). Viola $\times$ wittrockiana. (pp. 818-821). doi:10.1007/978-94-0178748-2_70

Lu, B., Li, M., \& Yin, R. (2016). Phytochemical content, health benefits, and toxicology of common edible flowers: A review (20002015). Critical Reviews in Food Science and Nutrition, 56(1), S130-S148. doi:10.1080/ 10408398.2015.1078276

Ponting, J. D., Watters, G. G., Forrey, R. R., Jackson, R., \& Stanley, W. L. (1966). Osmotic dehydration of fruits. Food Technology, 20(10), 125-128.

Rajasekar, D., Akoh, C. C., Martino, K. G., \& MacLean, D. D. (2012). Physico-chemical characteristics of juice extracted by blender and mechanical press from pomegranate cultivars grown in Georgia. Food Chemistry, 133(4), 1383-1393. doi:10.1016/ j . foodchem.2012.02.025

Rop, O., Mlcek, J., Jurikova, T., Neugebauerova, J., \& Vabkova, J. (2012). Edible flowers-a new promising source of mineral elements in human nutrition. Molecules, 17(6), 6672-6683. doi:10.3390/molecules17066672

Schulte, A. J., Droste, D. M., Koch, K., \& Barthlott, W. (2011). Hierarchically structured superhydrophobic flowers with low hysteresis of the wild pansy (Viola tricolor)-new design principles for biomimetic materials. Beilstein Journal of Nanotechnology, 2, 228-236. doi:10.3762/bjnano.2. 27

Shi, J., \& Le Maguer, M. (2000). Lycopene in tomatoes: Chemical and physical properties affected by food processing. Critical Reviews in Biotechnology, 20(4), 293-334. doi:10.1080/07388550091144212
Skowyra, M., Calvo, M., Gallego, M. G., \& Azman, N. A. M. (2014). Characterization of phytochemicals in petals of different colours from Viola $\times$ wittrockiana gams. and their correlation with antioxidant activity. Journal of Agricultural Science, 6, 93-105. doi:10.5539/jas.v6n9p93

Stojanovic, J., \& Silva, J. L. (2007). Influence of osmotic concentration, continuous high frequency ultrasound and dehydration on antioxidants, colour and chemical properties of rabbiteye blueberries. Food Chemistry, 101 (3), 898-906. doi:10.1016/j.foodchem. 2006.02.044

Tadesse, T. F., Abera, S., \& Worku, S. (2015). Nutritional and sensory properties of solardried carrot slices as affected by blanching and osmotic pre-treatments. International Journal of Food Science and Nutrition, 5(1), 24-32.

Trivellini, A., Gordillo, B., Rodriguez-Pulido, F. J., Borghesi, E., Ferrante, A., Vernieri, P., ... Heredia, F. J. (2014). Effect of salt stress in the regulation of anthocyanins and color of Hibiscus flowers by digital image analysis. Journal of Agricultural and Food Chemistry, 62 (29), 6966-6974. doi:10. 1021/jf502444u

Vijayanand, P., Chand, N., \& Eipeson, W. E. (1995). Optimization of osmotic dehydration of cauliflower. Journal of Food Processing and Preservation, 19(4), 229-242. doi:10.1111/j.1745-4549.1995.tb00291.x

Vukics, V., Kery, A., \& Guttman, A. (2008). Analysis of polar antioxidants in heartsease (Viola tricolor 1.) and garden pansy (Viola $x$ wittrockiana gams.) Journal of Chromatographic Science, 46(9), 823-827. doi:10.1093/chromsci/46.9.823

Weryszko-Chmielewska, E., \& Sulborska, A. (2012). Diversity in the structure of the petal epidermis emitting odorous compounds in Viola X Wittrockiana gams. Acta Scientiarum Polonorum-Hortorum Cultus, 11(6), 155-167.

Xin, Y., Zhang, M., \& Adhikari, B. (2013). Effect of trehalose and ultrasound-assisted osmotic dehydration on the state of water and glass transition temperature of broccoli (Brassica oleracea l. var. botrytis 1.) 
Osmotic drying of pansies $\mid 33$

Journal of Food Engineering, 119(3), 640647. doi:10.1016/j.jfoodeng.2013.06.035

Zhang, J., Wang, L.-S., Gao, J.-M., Xu, Y.-J., Li, L.-F., \& Li, C.-H. (2012). Rapid separation and identification of anthocyanins from flowers of Viola yedoensis and $V$. prionantha by high-performance liquid chromatography-photodiode array detection-electrospray ionisation mass spectrometry. Phytochemical Analysis, 23(1), 16-22. doi:10.1002/pca.1320 